\title{
Smoking status and oral health-related quality of life among adults in the United Kingdom
}

\author{
N. N. Bakri, ${ }^{* 1}$ G. Tsakos² and M. Masood ${ }^{3}$
}

\section{Key points}

Shows that the smoking status was independently associated with worse oral health-related quality life after adjusting with a range of social demographic predictors, clinical status and self-reported general health.
Provides evidence based argument in promoting health $\quad$ Encourages future studies on this area of interest. and oral health to public.

Objective The primary objective of this study was to examine the association between smoking and oral health-related quality of life (OHRQoL) among dentate people aged 16 years and above in England. Methods Cross-sectional study, based on the Adult Dental Health Survey (ADHS) 2009. ADHS 2009 involved data collection from 11,380 face-to-face interviews and 6,469 dental examinations from England, Wales and Northern Ireland. This study focuses on the dentate sample from England, consisting of 5,622 individuals who underwent dental examination. OHRQoL was measured by two indices; Oral Health Impact Profile-14 (OHIP-14) and Oral Impacts on Daily Performance (OIDP). Unadjusted and adjusted zero-inflated regression models were used. Adjustment was sequentially done for socio-demographics, clinical oral conditions and self-reported general health. Results Prevalence of those who had never smoked, past smokers and current smokers were $45.6 \%, 35.3 \%$ and $19.2 \%$ respectively. Current smokers had considerably higher mean OHIP-14 and OIDP scores than non-smokers. There was a statistically significant association between smoking and OHRQoL (both OHIP-14 and OIDP) even in the fully adjusted models. Current smokers were more likely to report worse OHRQoL compared to those who had never smoked in both OHIP-14 and OIDP score. There was no statistically significant difference between past smokers with those who had never smoked in reporting OHIP-14 and OIDP. Among those reporting OHRQoL, there was a stepwise gradient risk of reporting no oral impact, where the probability was higher among those who had never smoked, followed by past smokers and current smokers both in OHIP-14 and OIDP. Conclusion Smoking was independently associated with worse OHRQoL, even after adjusting for a range of socio-demographic factors, clinical oral conditions and self-reported general health.

\section{Introduction}

Many studies have shown the harmful effect of smoking behaviour in relation to oral cancer, ${ }^{1-3}$ periodontal disease incidence and tooth loss, ${ }^{4-8}$ precancerous lesions, ${ }^{9}$ dental caries ${ }^{10-12}$ and teeth staining. ${ }^{13,14}$ These oral conditions may affect the physical, psychological and social well-being of an individual..$^{15}$ For instance,

${ }^{1}$ Centre of Population Oral Health and Clinical Prevention Studies, Faculty of Dentistry, Universiti Teknologi MARA, Sungai Buloh Campus, 47000, Malaysia; ${ }^{2}$ Department

of Epidemiology and Public Health, University College

London, 1-19 Torrington Place, London, WC1E 7HB, United Kingdom.; ${ }^{3}$ Department of Dentistry and Oral Health, La

Trobe Rural Health School, La Trobe University, Melbourne,

3550, Australia

*Correspondence to: Dr Noor Nazahiah Bakri

Email: nazahiahb@yahoo.com

Refereed Paper. Accepted 5 March 2018

DOI: 10.1038/sj.bdj.2018.529 caries cause pain and discomfort from acute and chronic infection, which may disturb eating and sleeping. Coping with oral pain is one of the reasons for children's absence from school and this affects their school performance. ${ }^{16}$ Moreover, tooth loss affects chewing abilities, limits food choice and reduces the enjoyment of food intake. ${ }^{17}$ The impacts of smoking-related diseases have been felt at individual, societal and national level and the costs of treating these diseases are high worldwide. ${ }^{18,19}$

Oral health-related quality of life (OHRQoL) is the self-perceived impact of the oral conditions on the social, functional and psychological well-being of individuals. OHRQoL measures are used to capture the impact of oral conditions on the well-being of individuals. ${ }^{20}$ In addition, OHRQoL measures together with clinical measures and indicators of behavioural propensity, can be used to access the oral care need of individuals and populations in general. ${ }^{21,22}$

In the past three decades, researchers have been trying to comprehend which factors influence the subjective perception of quality of life. Many studies have successfully addressed the relationship between OHRQoL and health determinants including clinical conditions, socio-demographic and behavioural factors. ${ }^{23-26}$

As a common behavioural cause of preventable illness and death worldwide, many studies have observed on the role of smoking behaviour on quality of life among patients with general health problems such as cardiovascular diseases, respiratory problems and cancers. ${ }^{27}$ However, despite the harmful effects of smoking to oral health, the role of smoking on OHRQoL is not well-researched.

Few studies have examined the effect of 
smoking on OHRQoL from various countries. Maida et al..$^{25}$ and Sander ${ }^{28}$ examined the US national survey, Astrom et al..$^{29}$ examined people aged 50 years in Sweden using a longitudinal study ciluen

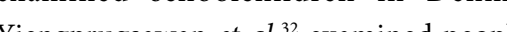
Yiengprugsawan et al." exanined people in a national cohort study and Espinoza et al." examined a nationally representative sample in Chili. One randomised experimental study among adults with human immune deficiency virus (HIV) looked at the impacts of HIV severity on OHRQoL. The study concluded that smoking has a strong correlation with OHRQoL among HIV patients. ${ }^{34}$ All three studies that looked directly on the association between smoking and OHRQoL found that smokers reported poorer OHRQoL compared to those who never smoked. $252.29,30$ Moreover, studies that looked indirectly on the association between smoking and OHRQoL did also support the association between smoking and poorer OHRQoL, , $8,3,3,3,3,34$ with the exception of only one study.3.

These studies employed different methodological designs, and also varied in the age of respondents and the chosen OHRQoL measure. With different methodology design, age of respondents, and OHRQoL measure used, it is difficult to make a direct comparison between these studies. Moreover, some of these studies used a validated OHRQoL measure while other studies used modified versions of $\mathrm{OHRQ} \mathrm{L}$ measure, therefore they are not directly comparable with other studies. In addition all previous studies relied on one indicator to measre OHRQDL None cxing $\mathrm{O}$ indicar, thereby allowing for comparsons. indicator, the dy allowng for comparisons Therefore, the aim of this study is to examine the relationship between smoking behaviour and OHRQoL among dentate people aged 16 years and above in England.

\section{Methodology}

This study examined data from the Adult Dental Health Survey (ADHS) 2009, taken from the UK data archives. ADHS 2009 has obtained the
ethical approval from the Oxfordshire Research ethical approval from the Oxfordshire Research
Ethics Committee. Secondary data analysis Ethics Committee. Secondary data analysis
does not require further ethical approval as no does not require further ethical approval as no personal or small area level identifiers were used in these analyses.

\begin{tabular}{|c|c|c|c|c|}
\hline Variable & Categories & n (\%) & Mean OHIP (se) & Mean OIDP (se) \\
\hline \multirow[t]{3}{*}{ Smoking } & Never & $2,523(45.6)$ & $2.9(0.1)$ & $4.0(0.2)$ \\
\hline & Past & 1,951 (35.3) & $3.3(0.1)$ & $4.0(0.2)$ \\
\hline & Current & 1,060 (19.2) & $6.4(0.3)$ & $8.7(0.5)$ \\
\hline Age group & $\begin{array}{l}16 \text { to } 34 \\
35 \text { to } 54 \\
55 \text { and over }\end{array}$ & $\begin{array}{l}1,335(24.1) \\
2,110(38.1) \\
2,089(37.8)\end{array}$ & $\begin{array}{l}3.6(0.2) \\
4.0(0.1) \\
3.5(0.1)\end{array}$ & $\begin{array}{l}5.4(0.3) \\
5.3(0.3) \\
4.1(0.2)\end{array}$ \\
\hline \multirow[t]{2}{*}{ Sex } & Male & $2,529(45.7)$ & $3.5(0.1)$ & $4.5(0.2)$ \\
\hline & Female & $3,005(54.3)$ & $4.0(0.1)$ & $5.2(0.2)$ \\
\hline Marital status & $\begin{array}{l}\text { Married /civil partner } \\
\text { Divorced/sparated/widowed } \\
\text { Single }\end{array}$ & $\begin{array}{l}3,096(56.0) \\
964(17.4) \\
1,474(26.6)\end{array}$ & $\begin{array}{l}3.4(0.1) \\
4.6(0.2) \\
3.9(0.2)\end{array}$ & $\begin{array}{l}4.2(0.2) \\
6.0(0.4) \\
5.6(0.3)\end{array}$ \\
\hline Education & $\begin{array}{l}\text { Degree or superior } \\
\text { Below degree } \\
\text { No qualifications }\end{array}$ & $\begin{array}{l}1,477(26.7) \\
3,248(58.7) \\
809(14.6)\end{array}$ & $\begin{array}{l}3.0(0.1) \\
3.9(0.1) \\
4.4(0.3)\end{array}$ & $\begin{array}{l}4.0(0.3) \\
5.1(0.2) \\
5.7(0.4)\end{array}$ \\
\hline Number of teeth & $\begin{array}{l}25-32 \\
17-24 \\
9-16 \\
1-8\end{array}$ & $\begin{array}{l}3,835(69.3) \\
1,213(21.9) \\
341(6.2) \\
145(2.6)\end{array}$ & $\begin{array}{l}3.1(0.1) \\
4.6(0.2) \\
6.2(0.5) \\
6.1(0.7)\end{array}$ & $\begin{array}{l}4.2(0.2) \\
5.8(0.4) \\
7.7(0.8) \\
7.6(1.1)\end{array}$ \\
\hline Active decay & $\begin{array}{l}\text { No } \\
\text { Yes }\end{array}$ & $\begin{array}{l}3,904(70.6) \\
1,630(29.5)\end{array}$ & $\begin{array}{l}3.1(0.1) \\
5.1(0.2)\end{array}$ & $\begin{array}{l}4.1(0.2) \\
6.8(0.3)\end{array}$ \\
\hline At least one PUFA & $\begin{array}{l}\text { No } \\
\text { Yes }\end{array}$ & $\begin{array}{l}5,180(93.6) \\
354(6.4)\end{array}$ & $\begin{array}{l}3.4(0.1) \\
8.3(0.5)\end{array}$ & $\begin{array}{l}4.4(0.1) \\
11.9(1.0)\end{array}$ \\
\hline $\begin{array}{l}\text { At least one } \\
\text { bleeding site }\end{array}$ & $\begin{array}{l}\text { No } \\
\text { Yes }\end{array}$ & $\begin{array}{l}2,481(44.8) \\
3,053(55.2)\end{array}$ & $\begin{array}{l}3.3(0.1) \\
4.1(0.1)\end{array}$ & $\begin{array}{l}4.3(0.2) \\
5.4(0.2)\end{array}$ \\
\hline $\begin{array}{l}\text { At least one pocket } \\
\geq 4 \mathrm{~mm}\end{array}$ & $\begin{array}{l}\text { No } \\
\text { Yes }\end{array}$ & $\begin{array}{l}2,895(52.3) \\
2,639(47.7)\end{array}$ & $\begin{array}{l}3.2(0.1) \\
4.3(0.1)\end{array}$ & $\begin{array}{l}4.4(0.2) \\
5.4(0.2)\end{array}$ \\
\hline $\begin{array}{l}\text { Self-reported } \\
\text { general health }\end{array}$ & $\begin{array}{l}\text { Very good/good } \\
\text { Fair } \\
\text { Very bad/ bad }\end{array}$ & $\begin{array}{l}4,521(81.7) \\
796(14.4) \\
217(3.9)\end{array}$ & $\begin{array}{l}3.1(0.1) \\
6.0(0.3) \\
8.0(0.7)\end{array}$ & $\begin{array}{l}4.0(0.2) \\
8.0(0.5) \\
11.6(1.2)\end{array}$ \\
\hline 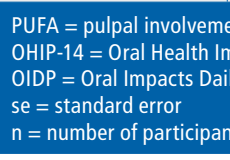 & $\begin{array}{l}\text { ent, ulceration, fistula and bibsess } \\
\text { pact Profile-14 }\end{array}$ & & & \\
\hline
\end{tabular}

from 11,380 face to face interviews and 6,469 psychological discomfort, physical disability, ental examinations. This study focuses on psychological disability, social disability and England thus leaving the original sample of handicap. ${ }^{35}$ For each question, answering 9663. Among the 8,017 dentate participants, options were 'Never' $=0$, 'Hardly ever' $=1$, 'Occasionally' $=2$, 'Fairly often' $=3$ and 'Very and hence were eligible for inclusion in this often' $=4$. The OHIP-14 score was calculated nalysis. Cases with missing value $(\mathrm{n}=88$, by adding the score of the 14 questions with $1.6 \%$ ) on any of the variables were excluded the range from zero to 56 . The higher score from the analysis

The outcome variable was OHRQoL. Two of

validated measures were used: the Oral Health The OIDP measures the frequency and Impact Profile (OHIP-14) and the Oral Impacts severity of oral impacts on the abilities to Daily Performances (OIDP). carry out nine daily activities; eating, speaking The OHIP-14 is a shortened version of cleaning teeth or dentures, going out, relaxing, OHIP-49 developed using a conceptual smiling, carrying out major role or work, mainmodel of oral health by Locker." The OHIP-14 taining emotional state and enjoying contact measures the frequency of oral impacts in seven with people. ${ }^{36}$ Severity of the oral impacts dimensions, two questions for each dimension, was assessed through a Likert scale ranging
namely; functional limitation, physical pain,

\begin{tabular}{|c|c|c|c|c|}
\hline \multirow[t]{2}{*}{ Variable } & \multirow[t]{2}{*}{ Categories } & \multicolumn{3}{|c|}{ Smoking (\%) } \\
\hline & & Never & Past & Current \\
\hline Age group & $\begin{array}{l}16 \text { to } 34 \\
35 \text { to } 54 \\
55 \text { and over }\end{array}$ & $\begin{array}{l}47.8 \\
48.4 \\
41.3\end{array}$ & $\begin{array}{l}25.2 \\
30.4 \\
46.6\end{array}$ & $\begin{array}{l}27.0 \\
21.2 \\
12.1\end{array}$ \\
\hline \multirow[t]{2}{*}{ Sex } & Male & 38.2 & 42.0 & 19.8 \\
\hline & Female & 51.8 & 29.6 & 18.6 \\
\hline Marital status & $\begin{array}{l}\text { Married/civil partner } \\
\text { Divorced/sparated/widowed } \\
\text { Single }\end{array}$ & $\begin{array}{l}47.3 \\
40.3 \\
45.6\end{array}$ & $\begin{array}{l}39.7 \\
36.2 \\
25.3\end{array}$ & $\begin{array}{l}13.1 \\
23.6 \\
29.1\end{array}$ \\
\hline Education & $\begin{array}{l}\text { Degree or superior } \\
\text { Below degree } \\
\text { No qualfications }\end{array}$ & $\begin{array}{l}54.1 \\
43.4 \\
38.8\end{array}$ & \begin{tabular}{|l}
36.0 \\
34.6 \\
36.6
\end{tabular} & $\begin{array}{l}9.9 \\
22.0 \\
24.6\end{array}$ \\
\hline Number of teeth & $\begin{array}{l}25-32 \\
17-24 \\
9-16 \\
1-8\end{array}$ & $\begin{array}{l}49.9 \\
38.6 \\
30.8 \\
24.8\end{array}$ & $\begin{array}{l}31.7 \\
41.0 \\
46.6 \\
55.2\end{array}$ & $\begin{array}{l}18.4 \\
20.5 \\
22.6 \\
20.0\end{array}$ \\
\hline Active decay & $\begin{array}{l}\text { No } \\
\text { Yes }\end{array}$ & $\begin{array}{l}47.6 \\
40.8\end{array}$ & \begin{tabular}{|l|}
37.0 \\
31.1
\end{tabular} & $\begin{array}{l}15.4 \\
28.1\end{array}$ \\
\hline At least one PUFA & $\begin{array}{l}\text { No } \\
\text { Yes }\end{array}$ & $\begin{array}{l}46.2 \\
36.7\end{array}$ & $\begin{array}{l}35.7 \\
28.8\end{array}$ & $\begin{array}{l}18.1 \\
34.5\end{array}$ \\
\hline $\begin{array}{l}\text { At least one bleeding } \\
\text { site }\end{array}$ & $\begin{array}{l}\text { No } \\
\text { Yes }\end{array}$ & $\begin{array}{l}45.4 \\
45.7\end{array}$ & \begin{tabular}{|l|}
37.5 \\
33.4
\end{tabular} & $\begin{array}{l}17.1 \\
20.9\end{array}$ \\
\hline $\begin{array}{l}\text { At least one pocket } \\
\text { depth } \geq 4 \mathrm{~mm}\end{array}$ & $\begin{array}{l}\text { No } \\
\text { Yes }\end{array}$ & $\begin{array}{l}48.8 \\
42.1\end{array}$ & \begin{tabular}{|l|}
34.8 \\
35.7
\end{tabular} & $\begin{array}{l}16.4 \\
22.2\end{array}$ \\
\hline $\begin{array}{l}\text { Self-reported general } \\
\text { health }\end{array}$ & $\begin{array}{l}\text { Very good/good } \\
\text { Fair } \\
\text { Very bad/bad }\end{array}$ & $\begin{array}{l}48.0 \\
36.6 \\
28.1\end{array}$ & $\begin{array}{l}35.0 \\
35.6 \\
40.1\end{array}$ & $\begin{array}{l}17.0 \\
27.9 \\
31.8\end{array}$ \\
\hline
\end{tabular}

The OIDP score was calculated by adding the below degree and no qualification).

scores from the nine items, then dividing this The oral clinical covariates considered by the maximum score (45) and multiplying it by 100 to get a percentage score. Higher OIDP indicates more severe alimpats.

The oral clinical covariates considered PUFA (pulpal involvement, ulceration, fistula and abscess), bleeding on probing (BOP) and Exposure variable was smoking status, used pocket depth. The number of natural teeth was smoking status, the specific questions was asked: "Have you ever smoked a cigarette, a cigar, or a pipe?' Individuals who answered 'Yes' were further asked 'And do you smoke cigarettes at all nowadays?' Answer for both questions were either 'Yes' or 'No. Individuals who answered ' $N o$ ' in the first question were categorised as 'never smoke', individuals who answered 'Yes' for the first and 'No' for the second question were categorised as 'past
smoker' and individuals who answered 'Yes' smoker' and individuals who answered 'Yes'
for both questions were categorised as 'current for both

smoker?

The socio-demographic covariates considered were age (16-34, 35-54, 55 and over.), sex (male or female), marital status (married/ civil partnership, separated/divorced/widowed and single) and education level (degree or superior in bivariate and multi-variable regression models. A series of sequential multi-variable
ZIP models were used, by calculating incidence rate ratios (IRR) for the non-zero OHRQoL ccores and odd ratio (OR) of hang (score of zero in the outcome)

\section{Results}

Data from 5,534 individuals was analysed in this study. Overall, $45.6 \%$ of the sample had never smoked, 35.3\% were past smokers and $19.2 \%$ were current smokers. The mean (standard error) OHIP scores was $2.9(0.1)$ among those that had never smoked, $3.3(0.1)$ among past smokers, and $6.4(0.3)$ among current smokers, while the respective means (standard (10) ) for the OIDP score were 4.0 $(0.2), 4.0(0.2)$ and $8.7(0.5)$ (Table 1). Table 2 shows the distribution of smoking status with other covariates.

Results for the associations between smoking and the OHIP14 score are presented in two different parts of the OHIP-14 score: a) as incidence rate ratios (IRR) for the OHIP-14 score among those with oral impacts (OHIP-14 $>0)$, and b) as odds ratios for having no oral impact (OHIP-14 $=0$ ).

Model 1 shows the crude (unadjusted) association of each variable with OHIP-14. The incidence rate (IRR) of having oral impacts (OHIP-14>0) in current smokers was $1.6(95 \%$ CI: 1.4, 1.8) when compared to those who had never smoked. However, past smokers had no difference in OHIP-14 score with those who had never smoked (IRR: 1.0: 95\% CI 0.9, 1.1). In terms of the zero-infted pat of the model (OHIP-14 = 0), cur past smokers had lower odds (OD. 0.5, 95\% CI: 0.40 .6 for car low C5\% CI: $0.7,0.9$ for pas mo for

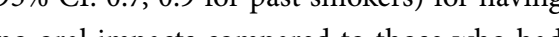
no oral impacts conpared to those who had

The aforementioned IRR for curren smokers attenuated slightly but remained statistically significant in Model 2 (adjusted for socio-demographic factors) and Model 3 (adjusted for socio-demographic factors and clinical oral conditions). In the zero-inflated part of the model (OHIP-14 $=0$ ), the respective estimates were unchanged in Model 2 and attenuated slightly while remaining statistically significant in Model 3

Model 4 presents the fully adjusted model for the association between smoking and OHIP-14 that accounted for socio-demographic factors clinical oral conditions and self-reported 

general health. Compared to those who never
smoked, current smokers had $1.3(1.2,1.5)$ times higher OHIP-14 score among those whe hor difference for $0.9,1.1)$. In tems of the zero-inflated part of the mode (OH $14=0$ ), current smokers and past smoks lawe odds (OR: $0.6-95 \%$ C. $0.5,0.7$; and 0 . 0.7 ; $95 \%$ C. $0.7,0.9$ respectively) for having no oral impacts when compared to those who had never smoked. Table 4 presents the associations between smoking and the OIDP score. Model 1 shows the crude (unadjusted) associations of each variable with OIDP. Among those with oral impacts (OIDP $>0$ ), current smokers had 1.4 (95\% CI: 1.2, 1.6) times higher OIDP score than those who had never smoked. The respective difference between past smokers and those who never smoked was not statistically significant (IRR: $0.9 ; 95 \% \mathrm{CI} 0.8,1.0$ ). In terms of the zero-inflated part of the model (OIDP $=0$ ), current smokers had lower odds (OR: $0.5 ; 95 \%$ CI: $0.4,0.6$ ) for having no oral smoked, while the respective estimate for past smokers was in the same direction but statistically non-significant (OR: $0.8 ; 95 \%$ CI: $0.7,1.0)$.

Similar to OHIP-14, the estimate for current smokers among those with oral impacts (OIDP $>0$ ) attenuated slightly but remained statistically significant in Model 2 (adjusted for socio-demographic factors) and Model 3 (adjusted for socio-demographic factors and clinical oral conditions). In the zero-inflated part of the model (OIDP $=0$ ) the resple estimases were unchanged in Models 2 and 3. Model 4 presents the fully adjusted mode mode 4 rised fhersocin after accounting clinical vartes and self-reported genera (OIDP $>0)$, carent times higher OIDP score than those who never smoked, while there was no difference for past smokers. For the zero-inflated part of the mode (OIDP $=0$ ), current smokers had lower odds
(OR: 0.6-95\% CI: 0.5, 0.7) for having no oral

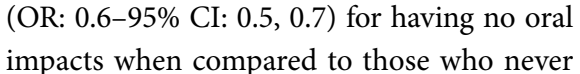
smoked. The OR of past smokers was not changed from the unadjusted model (Model 1) and remained the same throughout all models (OR: $0.8 ; 95 \%$ CI: $0.7,1.0$ ), showing a statistically non-significant association.

Discussion
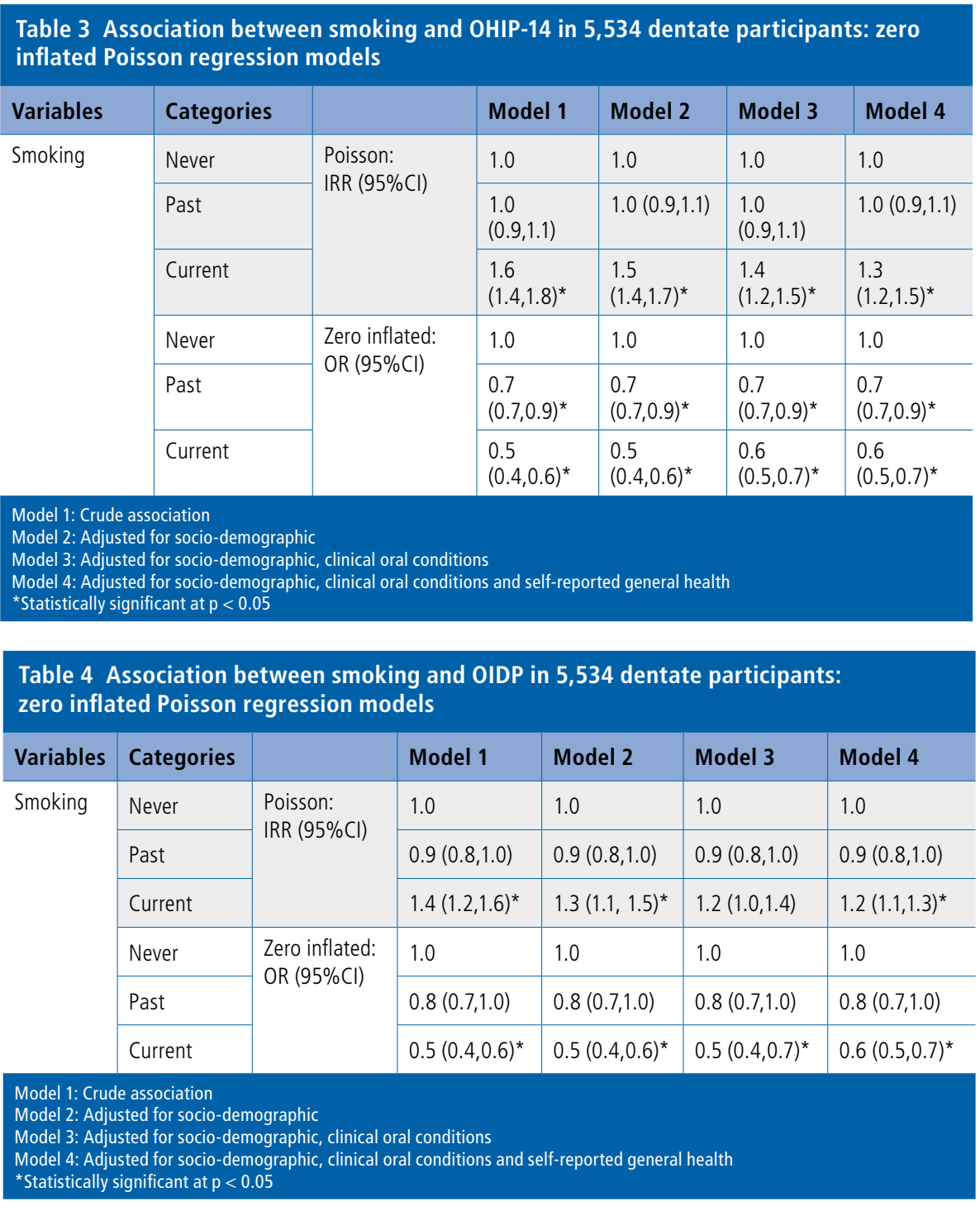

This study has shown that smoking was there was no difference in reporting OHRQoL statistically significant associated with oral among past smokers and those who had never OHRQoL and the results were very similar smoked. Astrøm et al..$^{9}$ found that males who for both the OHIP-14 and the OIDP. Among quit smoking at the age of 50 had higher risk those reporting oral impacts, current smokers of reporting oral impacts (OHRQoL) after were more likely to report worse OHRQoL 15 years compared to stable smokers. The cores compared to those who had never findings from another study supported that moked. However, there was no such differ- smoking is associated with worse OHRQoL netween past smokers and those who among secondary school children, but the had never smoked. Furthermore, there was study did not differentiate between past stepwise gradient risk of reporting no oral ${\text { smokers and never smokers. }{ }^{30}}^{30}$

mpact, with current smokers having the Unlike previous studies, it also showed a lowest probability of no oral impacts, followed stepwise association for the zero-inflated part by the past smokers when compared to those of the Poisson regressions, whereby there was lower prevalence of participants without oral The statistically significant association impacts for every group with less favourable etween smoking and OHRQoL from this smoking behaviour. Our study went further study was supported by three previous than the previous literature by looking at three studies ${ }^{52,29,30}$ though only the last study used a groups of smoking and also by separating the potentially comparable age group to our study. associations into two different parts through In line with our results, Maida et al. $2^{5}$ found the use of appropriate statistical techniques. that current smokers have worse OHRQoL and Indeed, the zero-inflated regressions allowed us to examine the association between smoking and OHRQoL scores for those that reported oral impacts and separately look at the odds of having no oral impacts between the three groups of smoking behaviour. Moreover, all previous studies used one OHRQoL measure, while we used the two most widely used and internationally comparable measures. This allowed us to compare our results across different $\mathrm{OHRQOL}$ measures and hence facilitate comprehensive assessment of the research question.

The main finding from this study suggests that smoking has an independent negative association towards OHRQoL. Therefore, public health action should focus on health promotion interventions against smoking, as
non-smokers are healthier and have better

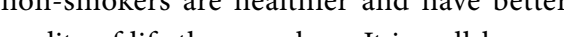
quality of life than smokers. It is well-known that smoking is harmful to oral and general health. Despite the preventive program, efforts and legislation that have been put against this behaviour, the prevalence of smoking both in men and women is still high in England. Our study has shown that people who smoked have worse OHRQoL compared to those who had never smoked and the risk of having poor OHRQoL in past smokers was the same as those who never smoke. The findings from this study may be used to emphasise the importance of smoking cessation programmes quality of life. For instances, it may be used to encourage people to stop smoking after being a smoker for a longer period. Rewards from not smoking goes beyond gaining better or of life.

A possible explanation is that people who do not smoke have a better life and feel happier, thus reported better OHRQoL, though this may be unrelated to their smoking experience. There is no direct evidence found to support this argument. However, previous studies have found that smoking is associated with depression, ${ }^{37-39}$ while ex-smokers reported that they were happier now than when they were smokers..$^{40}$ Another explanation may relate to the association whereby people with better OHRQoL enjoy their life more and are
happy, thus less likely to engage with unhealthy behaviours including smoking. ${ }^{4}$

ADHS followed a robust methodology in order to achieve a sample that was a national representation of adults in England, Wales and Northern Ireland. We analysed the dentate adult sample for England, which due to the nature of the study was quite large. In smoking rates and socio-demographic dition, all analyses in this study used survey background. The findings from this study weights to compenste for possible bias due to should be read with the understuding of the he nature of the sampling and the response mentioned potential bias. ate. Therefore the findings of our analyses, which only focus on the data for England, are eneralisable to the dentate adult population England.

is ADHS is a cross-sectional study. Therefore we cannot assess changes in smoking ehaviour and cannot infer causality from our findings. All secondary data analysis project we limited by the data available. Therefore were not able to gather more informatio smoking. For instance, there is no furthe formation on how long respondents have quit smoking, which may give an idea if tha person is a stable past smoker and can be categorised accordingly. Another example is th we were not able to have information on the amount of cigarettes smoked per day.

In addition to that, the question aske to classify past or former smokers is very troad, which cover someone who smokes one garette in his lifetime to someone who jus uit smoking a few days ago. This might overstimate the past smoker group and the impact ther oral health-related quality of e. A further recommendation for future oral health surveys is to include the relevant questions to categorise smoking status more and current smoker should be standardised allow robust analysis and comparison. Smoking statuses are more prone to to measure smoking status throug cabs monoxide concentration in expired ar serum concentration of cotinine in air and However, such methods were beyond the cope of the national epidemiogcal ora alth sury garettes smoked per day, or the length of time ce past smokers have quit smoking would ave allowed for a more comprehensive assessment of the association.

Another limitation of this study is selectio bias of the data included in this study. We included 5,622 dentate participants who (3) 2,395 dentate participants who did not have dental examination and 1,646 edentulous paricipants. They were excluded in the analysis they are missing data in oral clinical conditions which is needed for multi-variable regression analysis. Those excluded might have different characteristics for example,

\section{Conclusion}

This study has shown that smoking has a significant independent association with OHRQoL after accounting for the effect of socio-demographic background, clinical conditions and self-reported general health. Among those reporting oral impacts, current

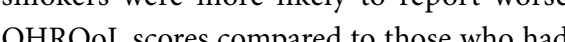
and crest se e who never smoked.

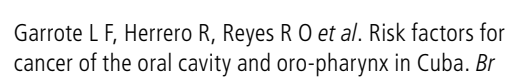

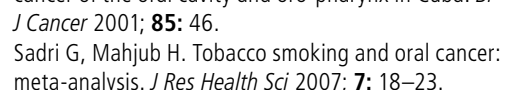

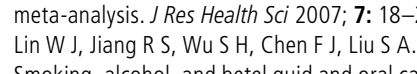
Smoking, alcohol, and betel quid and oral cancer: a
prospsective cocort tutudy. Oncol 2011; 20111: DOI: Bergström J. Cigarette smoking as risk factor in chronic
periodontal disease. Community Dent Oral Epidemiol

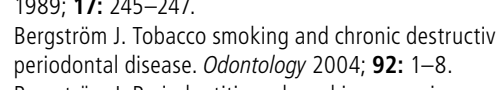
periodontal disease. Odontology 2004; 92: 1-8.
Bergström J. Periodontitis and mmoking: an evi-
dence-based appraisal. J Jvid Based Dent Pract 2006; 6 : $33-41$.
Water C, Kaye EK, Dietrich T. Active and passive smoking: assessment issues in periodont
Periodontology 2000 2012; $58:$ 84-92. Grover H S, Bhardwaj A, Singh Y. Smoking and Periodon-
tal Disease. J Pharm Sci Innovat 2013: 2: 7-13

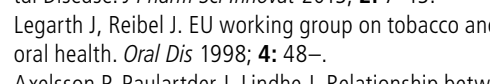

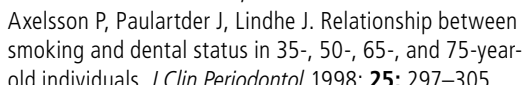
old individuals. J Clin Periododontol 1998; 25: 297-305.

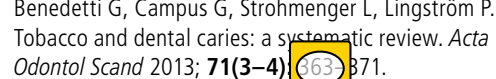
Golpasand Hagh et al. 2013. 1977; 5: 55-60. Watts A, Addy M. Tooth discolouration and staningy: a
review of the literature. Br Dent $J 2001 ; 190: 309$. ICan Dent Assoc 2007; 73: 155 Sheiham A. Oral health, general heath and quality of
life. Bull Word Heatth organ 2005; 83: 644 .

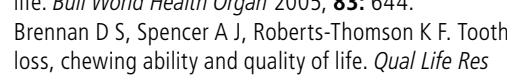
2008; $17: 227-235$. Co-related diseases, includiding passive smoking, in Hong
Kong. Tob Control 2006; 15: 125-130. Allender S, Balakrishnan R, Scarborough P, Webster P,
Rayner M. The burden of smoking-related ill health in

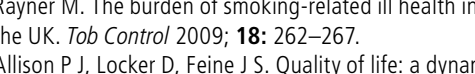
Allison PJ, Locker D, Feine S S. Quality of lifie: a dynam
construct. Soc Sci Med 1997; $45: 221-230$. Construct. Soc Sci Med 1997; 45: 221-230.
21. Gherunpong S, Tsakos G, Sheiham A. Ascoidentel for pas study of factors affecting extrinisic staining of teeth in 
ity in oral health-related qualityoflife, OHRQoL, at early older age: evidence from a prospective cohort study. Acta Odontol Scand 2011; 69: 334-342. and models. Int J Paediatr Dent 2006; 16: 81-88.

22. Tsakos G. Combining normative and psychosocial perceptions for assessing orthodontic treatment needs. J Dent Educ 2008; 72: 876-885.

23. Tsakos G, Marcenes W, Sheiham A. The relationship between clinical dental status and oral impacts in an elderly population. Oral Health Prev Dent 2004; 2: 211-220.

24. Daly B, Newton T, Batchelor P, Jones K. Oral health care needs and oral health related quality of life (OHIP-14) in homeless people. Community Dent Oral Epidemiol 2010; 38: 136-144.

25. Maida C A, Marcus M, Spolsky V W, Wang Y, Liu H. Socio-behavioral predictors of self-reported oral health-related quality of life. Qual Life Res 2013; 22: 559-566.

26. Kumar S, Kroon J, Lalloo R. A systematic review of the impact of parental socio-economic status and home environment characteristics on children's oral health related quality of life. Health Qual Life Outcomes 2014; 12: 41 .

27. World Health Organization. Global status report on noncommunicable diseases 2010, Italy. Available at http:/l www.who.int/nmh/publications/ncd report_full_en.pdf (accessed August 2014).

28. Sanders A E. A Latino advantage in oral health-related quality of life is modified by nativity status. Soc Sci Med 2010; 71: 205-211.

29. Åstrøm A N, Ekback G, Ordell S, Unell L. Social inequal-
30. Mbawalla H S, Masalu 」 R, Åstrøm A N. Sociodemographic and behavioural correlates of oral hygiene status and oral health related quality of life, the Limpopo-Arusha school health project (LASH): A cross-sectional study. BMC Pediatr 2010; 10: 87

31. Christensen L B, Hede B, Nielsen E. A cross-sectional study of oral health and oral health-related quality of life among frail elderly persons on admission to a special oral health care programme in Copenhagen City, Denmark. Gerodontology 2012; 29: 392-400.

32. Yiengprugsawan V, Somkotra T, Seubsman S A, Sleigh A C. Oral Health-Related Quality of Life among a large national cohort of 87,134 Thai adults. Health Qual Life Outcomes 2011: 9: 42

33. Espinoza I, Thomson W M, Gamonal J, Arteaga 0 . Disparities in aspects of oral-health-related quality of life among Chilean adults. Community Dent Oral Epidemiol 2013: 41: 242-250

34. Tomar S L, Pereyra M, Metsch L R. Oral health-related quality of life among low-income adults living with HIV. J Public Health Dent 2011; 71: 241-247.

35. Slade G D. Derivation and validation of a short-form oral health impact profile. Community Dent Oral Epidemiol 1997: 25: 284-290.

36. Adulyanon S, Vourapukjaru J, Sheiham A. Oral impacts affecting daily performance in a low dental disease Tha population. Community Dent Oral Epidemiol 1996; 24: 385-389.

37. Ziedonis D, Hitsman B, Beckham J C et al. Tobacco use and cessation in psychiatric disorders: National Institute of Mental Health report. Nicotine Tob Res 2008; 10: 1691-1715.

38. Hämäläinen J, Kaprio J, Isometsä E et al. Cigarette smoking, alcohol intoxication and major depressive episode in a representative population sample. J Epidemiol Community Health 2001; 55: 573-576.

39. Harlow B L, Cohen L S, Otto M W, Spiegelman D, Crame D W. Prevalence and predictors of depressive symptoms in older premenopausal women: the Harvard Study of Moods and Cycles. Arch Gen Psychiatry 1999; 56: 418-424.

40. Harlow B L, Cohen L S, Otto M W, Spiegelman D, Cramer $D$ W. Prevalence and predictors of depressive symptoms in older premenopausal women: the Harvard Study of Moods and Cycles. Arch Gen Psychiatry 1999; 56: 418-424.

41. Piqueras J A, Kuhne W, Vera-Villarroel P, Van Straten A, Cuijpers P. Happiness and health behaviours in Chilean college students: a cross-sectional survey. BMC Pub Health 2011; 11: 443

42. Klesges R C, Debon M, Ray J W. Are self-reports of smoking rate biased? Evidence from the Second National Health and Nutrition Examination Survey. J Clin Epidemiol 1995; 48: 1225-1233.

43. Hald J, Overgaard J, Grau C. Evaluation of objective 